\title{
HIP MONOARTHRITIS AS A MANIFESTATION OF CHIKUNGUNYA IN CHILDHOOD: CASE REPORT
}

Angélica Maria Assunção da Ponte Lopes ${ }^{1, \star}$, Roberta Oriana Assunção Sousa da Ponte Lopes², Anna Beatriz Carvalho de Oliveira ${ }^{1}$, Isabella Nunes Veloso ${ }^{1}$, Felipe Leite Feitosa ${ }^{1}$, Lucas Lins Marques1, Bárbara Santos Accioly Calumby ${ }^{1}$, Lucas Martins de Carvalho ${ }^{1}$

1.Centro Universitário UniFacid Wyden, Teresina (PI), Brazil. 2.Hospital Infantil Lucídio Portela, Teresina (PI), Brazil.

${ }^{\star}$ Corresponding author: angelica.mariaapl@gmail.com

\section{BACKGROUND}

Chikungunya is an arbovirus that has arthritis as a major symptom, usually polyarticular, bilateral and symmetrical, accompanied by fever.

\section{CASE REPORT}

Male patient, 8 years old, presented fever and arthritis in the right hip joint with difficulty walking for 15 days. Physical examination: eupneic, hydrated, anicteric, acyanotic, afebrile. Absence of palpable lymph nodes. No cardiac and respiratory changes. Flat abdomen, depressible, painless to superficial and deep palpation, without visceromegaly. Limitation to internal and external rotation of the right hip. Complementary exams: right hip ultrasound with joint effusion in the right hip joint. Laboratory tests: Hb: 12.5 mg/dL, Ht: 35.9\%, leukocytes: 4000, Rods: 2, eosinophils: 3, lymphocytes: 48, platelets: 128,000, PCR: negative, ASLO: negative, HLA B27: absent, sickling test: negative. Chikungunya serology: IgM reagent and IgG nonreagent. The patient used naproxen showing clinical improvement.

\section{CONCLUSION}

Although uncommon, monoarthritis can be an articular manifestation of Chikungunya and the inclusion of this arbovirus among the differential diagnoses of acute monoarthritis in childhood is pertinent. 